This item was submitted to Loughborough's Research Repository by the author.

Items in Figshare are protected by copyright, with all rights reserved, unless otherwise indicated.

\title{
Midwives are getting hurt: UK survey of the prevalence and risk factors for developing musculoskeletal symptoms
}

PLEASE CITE THE PUBLISHED VERSION

https://doi.org/10.1016/j.midw.2019.102546

PUBLISHER

Elsevier BV

VERSION

AM (Accepted Manuscript)

PUBLISHER STATEMENT

This paper was accepted for publication in the journal Midwifery and the definitive published version is available at https://doi.org/10.1016/j.midw.2019.102546

LICENCE

CC BY-NC-ND 4.0

\section{REPOSITORY RECORD}

Okuyucu, Kubra, Diane Gyi, Sue Hignett, and Angie Doshani. 2019. "Midwives Are Getting Hurt: UK Survey of the Prevalence and Risk Factors for Developing Musculoskeletal Symptoms". figshare.

https://hdl.handle.net/2134/9970271.v1. 
Midwives are getting hurt: UK survey of the prevalence and risk factors for developing musculoskeletal symptoms

Kubra Okuyucu, Diane Gyi, Sue Hignett, Angie Doshani

PII:

DOI:

Reference:

To appear in:

Received date:

Revised date:

Accepted date:
S0266-6138(19)30237-2

https://doi.org/10.1016/j.midw.2019.102546

YMIDW 102546
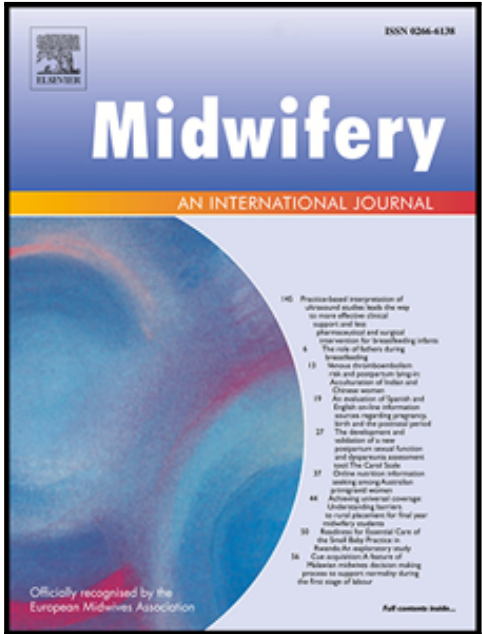

Please cite this article as: Kubra Okuyucu, Diane Gyi, Sue Hignett, Angie Doshani, Midwives are getting hurt: UK survey of the prevalence and risk factors for developing musculoskeletal symptoms, Midwifery (2019), doi: https://doi.org/10.1016/j.midw.2019.102546

This is a PDF file of an article that has undergone enhancements after acceptance, such as the addition of a cover page and metadata, and formatting for readability, but it is not yet the definitive version of record. This version will undergo additional copyediting, typesetting and review before it is published in its final form, but we are providing this version to give early visibility of the article. Please note that, during the production process, errors may be discovered which could affect the content, and all legal disclaimers that apply to the journal pertain.

(C) 2019 Published by Elsevier Ltd. 
Midwives are getting hurt: UK survey of the prevalence and risk factors for developing musculoskeletal symptoms

\section{Title}

Midwives are getting hurt: UK survey of the prevalence and risk factors for developing musculoskeletal symptoms

\section{Author names and affiliations}

Kubra Okuyucu ${ }_{1}$, Diane Gyi ${ }_{1}$, Sue Hignett ${ }_{1}$, Angie Doshani 2

1. Loughborough University, LE11 3TU, UK

2. University Hospitals of Leicester, LE5 4PW, UK

Corresponding author-Kubra Okuyucu, Email: k.arslan@lboro.ac.uk, Twitter: @ArslanKbra

\section{Conflict of Interest - None declared}

Ethical Approval - This research was approved by Loughborough University Ethics committee and further approvals were confirmed as part of the Health Research Authority of the UK

Funding Sources - This research did not receive any specific grant from funding agencies in the public, commercial, or not-for-profit sectors.

\section{Abstract}

Objective - To investigate the prevalence, severity and impact of musculoskeletal disorders (MSDs) and to explore individual, work-related and psychosocial risk factors

Design - A cross sectional survey

Setting - A self-reported online questionnaire was used to collect data over seven months (May-December 2016).

Participants - The survey was distributed to midwives across the United Kingdom through the Consultant Midwives Network and the Royal College of Midwives.

Measurements and findings - Prevalence, severity and impact (12-month) of MSDs for nine body parts are presented. The associations between individual, occupational and psychosocial factors and symptoms are examined using Independent samples t-test or Chi- 
square statistical analyses, with Logistic regression analysis to understand the relative importance of variables. It was found that $92 \%$ of the participants reported MSDs, most commonly in the low back (71\%), neck (45\%) and shoulders (45\%). Symptoms impacted on normal activities at work and/or leisure (50\%), sick leave (30\%) and jobs/duties (45\%). Age and time practicing in midwifery were inversely associated with low back symptoms; reported less frequently with increasing age and experience. Longer working hours was a predictor for shoulder symptoms. Over commitment (intrinsic job stress) was associated with neck and more strongly with shoulder symptoms. Those caring for a dependent adult for more than 50 hours a week were 4.54 times more likely to have neck discomfort.

Key conclusions - This first survey of UK Midwives reveals a very high prevalence of low back, neck and shoulder symptoms, resulting in sickness absenteeism, reduction in normal activities and changing roles. Age, years in practice, body mass index, working hours, job satisfaction and job stress are contributory factors.

Implications for practice - This study highlights the prevalence and impact of musculoskeletal symptoms and the potential harmful impacts on their working life and patient care. The findings will promote risk-awareness and national actions for risk management.

Key words

Musculoskeletal disorders, pain, midwives, risk factors Introduction

Musculoskeletal Disorders (MSD) are a common problem in the working population resulting in sickness absenteeism, with considerable financial cost and a negative impact on quality of life and productivity at work. MSD was noted as the main reason given for sickness absence in the UK workforce over the last 20 years (Office for National Statistics, 2018). These data also indicated that people working in public health organisations had the highest sickness absence rate among all sectors including industrial workers. In the US, the health care sector also reported a considerably higher rate of occupational injuries than other sectors; 8 \% of cases were work-related injuries or disorders in 2014 (Bureau of 
Labour Statistics, 2015). For example, the rate of cases reported in non-governmental health care sector was 5\%, while mining, manufacturing, and transportation sectors had fewer cases (4\%) in 2014.

There has been an increase in retirement and pension ages for healthcare staff, (including midwives) to deal with the staff shortages (NHS Employers, 2015). This contributes to an increasing age profile of UK midwives; for example between 2010 and 2016, the number of National Health Services (NHS) midwives aged under 50 has fallen, and, In 2016 one third of NHS midwives were over 50 years old. Although older staff are valuable for their years of experience, their productivity at work could be lower due to the physiological consequences of ageing such as decrease in muscle strength and flexibility (Saxon et al., 2014); as such they may choose or move less physically demanding roles such as management or clinic in the years prior to retirement.

Nurses and midwives represent more than $50 \%$ of global shortage in healthcare staff (World Health Organisation, 2018). The shortage of midwives has recently been an issue in the UK (RCM, 2018). For example, a shortage of around 3,500 midwives in England in 2016 was announced based on a calculation of midwifery work demand (RCM, 2016). Over the years, the work demands in midwifery have been a challenge because of the increase in birth levels with more women being pregnant at older ages and overweight/obesity resulting in more complex cases. This shortage can contribute to musculoskeletal symptoms due to increased work demand on the rest of the workforce.

Ball et al. (2002) found that UK midwives left the profession because of dissatisfaction with midwifery, mainly due to the demands the work placed on them. A recent survey exploring the reasons for UK midwives leaving also showed that the top three reasons were dissatisfaction with staffing levels (52\%), the quality of care they provide (48\%) and the workload (39\%). The midwifery data do not show that MSD are a reason to leave the profession, but there is a wealth of literature (mainly about nurses), showing the association between heavy workload (e.g. long working hours, $>12$ hours shifts) and risk of MSD (Engkvist et al., 2000; Lipscomb et al., 2002; Trinkoff et al., 2006). 
Hignett (1996) studied manual handling risk factors for UK midwives using observation and interviews. This study highlighted the main factors specific to midwives to be that 1 ) they are caring two loads (mother and baby), and 2) the delivery being mother-centred i.e. the mother chooses her own position which might not be comfortable for the midwife. Physical workload factors, such as mainly working in awkward positions and manual lifting are the most obvious contributory factors for MSD in health professionals (Long et al., 2012; Russo et al., 2002). Long et al. (2013b) found that neck and upper back injuries (prevalence rates were $41 \%$ and $25 \%$ respectively) were common in Australian midwives, and significantly associated with 'awkward postures'

Psychosocial factors at work (e.g. too much overtime, high mental pressure, inadequate work support, and inadequate work discussion) are potential antecedents for the development of MSDs, as well as working characteristics and physical exposures (Hauke et al., 2011; Smedley et al., 2003; Smith et al., 2006), with people experiencing MSD-related pain likely to report anxiety and fear. Stress can also be a predictor of severe somatic symptoms (Lang et al., 2012). A 'biopsychosocial approach' has been used to evaluate and understand the contributory risk factors for MSD in terms of the body itself (bio-), behaviour (-psycho-) and the environment (-social) (Bartys, 2003; Gatchel et al., 2007; Laisné et al., 2013).

Management plans to prevent or reduce MSD should start by understanding the risk factors (Hignett, 2003; Van Mechelen et al., 1992; Yazdani et al., 2015). Midwives are at high risk of developing MSD at work which results in lost working days, leaving the profession and impacts on patient care resulting significant financial implications. which can affect quality of care and patient safety, although there is limited reported data on UK midwives. A comprehensive approach is necessary to understand the risk factors in detail in order to develop prevention strategies. This paper reports a survey to investigate;

- Prevalence, severity and impact of musculoskeletal symptoms

- Individual, work-related and psychosocial risk factors for musculoskeletal symptoms 


\section{Methods}

A self-reported online questionnaire was used to collect data. Musculoskeletal symptoms were investigated based on the Nordic Musculoskeletal Questionnaire (NMQ), which is commonly used to record work-related MSD (Kuorinka et al., 1987). Respondents were asked whether they had experienced musculoskeletal symptoms in nine body parts (neck, shoulders, upper back, elbows, wrists/hands, lower back, hips/thighs, knees, ankles/feet) during the last 12 months. Severity of the symptoms was addressed with the question of 'Has the trouble caused you to reduce your normal activity (work or leisure) during the last 12 months?' The impact of such symptoms was explored with questions about work modification and missed days off work due to MSD. In addition, midwives were asked about strategies used to manage their symptoms such as medication, being seen by a doctor or physiotherapist. Their views of such symptoms were also explored.

An extended version of this questionnaire was identified asking such questions for nine body parts. Throughout this section of the questionnaire, participants were reminded that they should respond according to their symptoms in specific body areas.

All of the questions in the survey were designed with multiple-choice responses and rating scales to increase the response rate, and ease the data analysis (Robson and McCartan, 2016). Some questions included the response choice of 'other', 'I can't remember' or 'prefer not to say' to improve the accuracy.

Individual, occupational and psychosocial risk factors, identified in the previous studies (Anderson and Oakman, 2016; Long et al., 2013b), were explored in order to understand the impact of such factors on the risk of MSD. Individual related factors included age, gender, weight, height, smoking, physical activity level, marital status, sleeping hours, being a carer for a child or an adult at home. Age, height and weight were requested and Body Mass Index (BMI) was calculated and grouped according to World Health Organisation scale (2016) as underweight, normal weight, overweight and obese. Physical activity levels were categorised as low, medium or high as advised by National Health Services (NHS) guidelines for adults, aged 19 to 64 (NHS, 2011). 
Occupational related factors were years of work experience; working hours in a week; duration of a shift work; proportion of night shift and breaks. Psychosocial factors were assessed by using the short version of the Effort-Reward Imbalance (ERI) questionnaire consisting of three main scales: effort, reward and over commitment (Siegrist et al., 2009). Of these components, the effort reward ratio represents extrinsic work stress, while over commitment represents intrinsic work stress. Each question is measured using a 4-point Likert scale: 1- strongly disagree, 2-disagree, 3- agree, 4 -strongly agree. The sum of each group, followed by division of the effort scores by reward scores, and multiplication of the final score by a correction factor produces an ER (Effort-Reward) score (Siegrist et al., 2013). Where ER $>1$, the person reports more effort for the reward, and where $E R<1$, there are less efforts for each reward. The data is interpreted for descriptive purposes showing the job stress level. Job satisfaction level was also recorded on a 10 point scale, 0 representing 'not satisfied at all' and 10 representing 'completely satisfied'.

This research was approved by Loughborough University Ethics committee and further approvals were confirmed as part of the Health Research Authority of the UK (HRA). The questionnaire was anonymised. The data were collected over a seven-month period (May to December 2016). It was disseminated to midwives, irrespective of whether they had an injury or not, across the UK through the Consultant Midwives Network and the Royal College of Midwives (RCM). The Consultant Midwives in each Trusts were contacted to send the survey link to their team, then regular reminders were sent to encourage their team to complete the survey. The RCM is the only professional organisation for midwives and represents approximately $90 \%$ of all UK midwives. Number of midwives at the time when the data collected was around 26,000 (RCM, 2015). The RCM published the survey on their website and official social media (Twitter) account. Multiple methods were also used to publicise the survey during this period to potential participants both locally and nationally (e.g. e-news, a poster including a QR code of the survey link and publishing at the annual conference).

Data were uploaded and analysed using IBM SPSS Statistics 23. Descriptive statistics were used to present characteristics of the samples and the prevalence rates. Bivariate analysis were used to understand the relationship between MSD and risk factors. 
Results

A total of 637 midwives across the UK responded to the questionnaire. Only two of these were excluded leaving a sample of 635 qualified midwives. Although there were some incomplete questions from the remaining participants, these respondents were included and a pairwise exclusion method was used to deal with the missing data. Table 1 contains a summary of the main characteristics of these midwives. The majority were female (only one male) and the mean age was $42.7(S D=11.5)$ years. Mean $B M I$ was $27.73(S D=5.53)$ and only $34.8 \%$ of the respondents were in the normal range of $\mathrm{BMI}$, the remaining were either overweight (30.4\%) or obese (30.2\%). Mean years practicing in midwifery was 15 $(S D=11.10)$, and $43.8 \%$ of the cohort reported working part time (less than 37.5 hours in a week). Over half of the midwives (66.3\%) reported working in a maternity unit in a hospital, mostly based in England (84.6\%). A normal shift was $8-12$ hours for $44.5 \%$ of the respondents, whereas $39.6 \%$ of them reported working more than 12 hours in a shift. The rest $(15.9 \%)$ reported shift hours of less than eight hours. The majority of the respondents (73.5\%) were married or in a domestic partnership and nearly half had children at home requiring care, and $28 \%$ reported caring more than 50 hours a week. One in five of the midwives reported having an adult dependant at home, but only a few were caring more than 50 hours a week.

Table 1: Characteristics of the participants included in the study

\begin{tabular}{|c|c|c|c|}
\hline Characteristics & $\begin{array}{c}\text { Number of } \\
\text { participants } \\
\text { completing the item }\end{array}$ & $\mathbf{N}(\%)$ or mean (SD) & Range \\
\hline $\begin{array}{l}\text { Gender } \\
\text { Female } \\
\text { Male } \\
\text { Missing }\end{array}$ & 614 & $\begin{array}{l}613(96.5 \%) \\
1(0.2 \%) \\
21(3.3 \%)\end{array}$ & $\mathrm{N} / \mathrm{A}$ \\
\hline Age & 630 & $42.76(11.46)$ mean(SD) & $19-67$ \\
\hline BMI & 610 & 27.73 (5.53) mean(SD) & $16.7-47.8$ \\
\hline Practice years in midwifery & 627 & 14.88 (11.10) mean(SD) & $1-46$ \\
\hline $\begin{array}{l}\text { Working hours in a week } \\
\text { Full-time } \\
\text { Part-time }\end{array}$ & 635 & $\begin{array}{l}32.52(8.05) \text { mean(SD) } \\
357(56.2 \%) \\
278(43.8 \%)\end{array}$ & \\
\hline $\begin{array}{l}\text { Working time involved delivering } \\
\text { (days in a week) }\end{array}$ & 607 & 2 (1.62) mean(SD) & $0-7$ \\
\hline $\begin{array}{l}\text { Work place setting } \\
\text { Maternity unit in a hospital } \\
\text { Midwife-led unit in a hospital } \\
\text { Standalone midwifery unit } \\
\text { Community } \\
\text { Missing }\end{array}$ & 619 & $\begin{array}{l}421(66.3 \%) \\
50(7.9 \%) \\
26(4.1 \%) \\
122(19.2 \%) \\
16(2.5 \%)\end{array}$ & N/A \\
\hline $\begin{array}{l}\text { Proportion of night shift in a month } \\
0 \%\end{array}$ & 625 & $217(34.2 \%)$ & $\mathrm{N} / \mathrm{A}$ \\
\hline
\end{tabular}




\begin{tabular}{|c|c|c|c|}
\hline $\begin{array}{l}25 \% \\
50 \% \\
75 \% \\
100 \% \\
\text { Missing }\end{array}$ & & $\begin{array}{l}171(26.9 \%) \\
156(24.6 \%) \\
54(8.5 \%) \\
27(4.3 \%) \\
10(1.6 \%)\end{array}$ & \\
\hline $\begin{array}{l}\text { Normal shift duration } \\
<8 \text { hours } \\
8 \text { hours - up to } 12 \text { hours } \\
>12 \text { hours } \\
\text { Missing }\end{array}$ & 629 & $\begin{array}{l}100(15.7 \%) \\
280(44.1 \%) \\
249(39.2 \%) \\
6(0.9 \%)\end{array}$ & N/A \\
\hline $\begin{array}{l}\text { Number of babies delivered in the } \\
\text { unit annually }\end{array}$ & 595 & 4802 (2885.91) mean(SD) & $0-14000$ \\
\hline $\begin{array}{l}\text { Marital status } \\
\text { Single, never married } \\
\text { Married or domestic partnership } \\
\text { Widowed, divorced, separated } \\
\text { Missing }\end{array}$ & 630 & $\begin{array}{l}110(17.3 \%) \\
463(72.9 \%) \\
57(9 \%) \\
5(0.8 \%)\end{array}$ & N/A \\
\hline $\begin{array}{l}\text { Carer for children } \\
\text { No } \\
\text { Yes, 1-19 hours a week } \\
\text { Yes, 20-49 hours a week } \\
\text { Yes, > } 50 \text { hours } \\
\text { Missing }\end{array}$ & 632 & $\begin{array}{l}344(54.2 \%) \\
70(11 \%) \\
41(6.5 \%) \\
177(27.9 \%) \\
3(0.5 \%)\end{array}$ & N/A \\
\hline $\begin{array}{l}\text { Carer for adult } \\
\text { No } \\
\text { Yes, 1-19 hours a week } \\
\text { Yes, 20-49 hours a week } \\
\text { Yes, > 50 hours } \\
\text { Missing }\end{array}$ & 632 & $\begin{array}{l}504(79.4 \%) \\
92(14.5 \%) \\
17(2.7 \%) \\
19(3 \%) \\
3(0.5 \%)\end{array}$ & N/A \\
\hline $\begin{array}{l}\text { Smoking } \\
\text { Formerly/Never } \\
\text { Currently a smoker } \\
\text { Missing }\end{array}$ & 630 & $\begin{array}{l}596(93.9 \%) \\
34(5.4 \%) \\
5(0.8 \%)\end{array}$ & N/A \\
\hline $\begin{array}{l}\text { Physical activity level } \\
\text { Low } \\
\text { Medium } \\
\text { High } \\
\text { Missing }\end{array}$ & 632 & $\begin{array}{l}314(49.4 \%) \\
282(44.4 \%) \\
36(5.7 \%) \\
3(0.5 \%)\end{array}$ & N/A \\
\hline $\begin{array}{l}\text { Country } \\
\text { England } \\
\text { Northern Island } \\
\text { Scotland } \\
\text { Wales } \\
\text { UK Islands } \\
\text { Missing }\end{array}$ & 629 & $\begin{array}{l}532(83.8 \%) \\
12(1.9 \%) \\
51(8 \%) \\
26(4.1 \%) \\
8(1.3 \%) \\
6(0.9 \%)\end{array}$ & N/A \\
\hline
\end{tabular}

N: Number; SD: Standard Deviation; N/A: Not applicable

\section{Prevalence and severity of MSD}

The prevalence of musculoskeletal symptoms was calculated as the percentage of those reporting MSD in nine body areas over a 12-month period. $97.5 \%$ of the midwives reported that they had experienced MSD at some time in their lives ( $n=619) .12$-month prevalence rates showed $91.5 \%(n=581)$ of the respondents reporting MSD, most commonly in the low back (71.4\%), followed by the neck (45.3\%) and shoulders (44.5\%) (Table 2 ). Of those who reported low back symptoms during the last 12 months, most (64.5\%) had symptoms for 
more than 30 days or every day. Similarly, the shoulders, hips/thighs, knees and ankles/feet symptoms were commonly experienced for more than 30 days or every day during the year. Half of these respondents (50.7\%) thought that their symptoms caused a reduction in leisure and work activities.

It is worrying that a third of the all respondents reported being hospitalised due to MSD; most commonly low back (10\%), knee (5.8\%) and shoulder (4.3\%) problems. In addition, almost half (45\%) had to change jobs or duties because of the symptoms they experienced. With regard to sick leave, $30.4 \%$ of the participants required sick leave due to musculoskeletal problems during the last year. Of those, almost half of them were due to low back symptoms which required typically one to seven days of sick leave. Most of those with shoulder symptoms (56\%) had sick leave for more than 30 days.

The majority of the midwives ( $n=385,60.6 \%$ ) were seen by a GP or other health professional, and most commonly due to low back, shoulder and neck symptoms. However, many of them self-managed their symptoms or were seen by a physiotherapist or occupational therapist. Anti-inflammatory drugs were most commonly taken for medication, followed by simple pain killers. 74 cases were given injections, of those majority $(n=24,32 \%)$ were due to shoulder problems.

Over half of the participants (56.5\%) with some kind of musculoskeletal symptom believed that they were solely due to activities at work, while others (34.5\%) either attributed them to combination of both leisure and work activities, or leisure activities only (9\%).

Table 2: 12-month prevalence of MSD, severity and sick leave in UK midwives

\begin{tabular}{|c|c|c|c|}
\hline Body area & $\begin{array}{c}\text { 12-month } \\
\text { prevalence } \\
\text { (n=635) }\end{array}$ & $\begin{array}{c}\text { Severity } \\
\text { (reduction in } \\
\text { normal activity) } \\
\text { prevalence } \\
\text { (n=633) }\end{array}$ & $\begin{array}{c}\text { Sick leave } \\
\text { (n=635) }\end{array}$ \\
\hline Neck & $\mathbf{( \% )}$ & $\mathbf{( \% )}$ \\
\hline Shoulders & 45.3 & 18.3 & 2.8 \\
\hline Upper back & 44.5 & 24.6 & 5.5 \\
\hline Elbows & 29.5 & 14.5 & 2.2 \\
\hline Wrists/hands & 12.3 & 5.4 & 1.2 \\
\hline Low back & 25.6 & 13.1 & 2.8 \\
\hline Hips/thighs & 71.4 & 50.7 & 17.3 \\
\hline Knees & 28.9 & 19.5 & 5.4 \\
\hline
\end{tabular}


Individual risk factors for MSD

There was a significant difference by age in the 12-month prevalence of upper back, low back and knees (Table 3), other body parts did not reach statistical significance $(p \leq 0.05)$. Participants who reported upper back and low back symptoms were younger on average than those who did not, whereas knee symptoms were more commonly reported by increasing age.

Table 3: Differences found from the comparison of age by musculoskeletal symptoms Yes and No groups for the 12-month period

\begin{tabular}{|c|c|c|c|c|}
\hline \multirow[t]{2}{*}{ Body area } & \multicolumn{2}{|c|}{ Mean age years $(S D)$} & \multirow[t]{2}{*}{$\mathbf{t}$} & \multirow{2}{*}{$\begin{array}{l}\text { Significance } \\
\text { level }\end{array}$} \\
\hline & MSD Yes & MSD No & & \\
\hline Neck & $42.16(11.43)$ & $43.17(11.45)$ & -1.09 & $p=0.2$ \\
\hline Shoulders & $42.68(11.22)$ & $42.73(11.64)$ & -0.53 & $p=0.9$ \\
\hline Upper back & $39.33(11.41)$ & $44.13(11.17)$ & -4.89 & $\mathrm{p}<0.0001 * * *$ \\
\hline Elbows & $43.96(11.18)$ & $42.54(11.48)$ & 1.02 & $p=0.3$ \\
\hline Wrists/hands & $42.87(11.54)$ & $42.66(11.42)$ & 0.2 & $p=0.8$ \\
\hline Low back & $41.71(11.41)$ & $45.23(11.16)$ & -3.51 & $\mathrm{p}<0.0001 * * *$ \\
\hline Hips/thighs & $43.76(11.61)$ & $42.28(11.36)$ & 1.47 & $p=0.1$ \\
\hline Knees & $44.24(11.30)$ & $42.00(11.45)$ & 2.29 & $p=0.02 *$ \\
\hline Ankles/feet & 44.15 (11.79) & $42.28(11.31)$ & 1.71 & $p=0.08$ \\
\hline
\end{tabular}

${ }^{*} \mathrm{p}<0.05 ; * * \mathrm{p}<0.01 ;{ }^{* * *} \mathrm{p}<0.001$

The 12-month prevalence of knee and ankle/foot symptoms were related to $\mathrm{BMI}$; midwives who reported knee $(p=0.007)$ and ankle/foot $(p<0.0001)$ symptoms had a significantly higher BMI on average than those who did not. A significant difference was also found between physical activity level and 12-month prevalence of hip/thigh, knee and ankle/foot symptoms (Figure 1); midwives with a low physical activity level were more likely to report musculoskeletal symptoms in the hips/thighs, knees and ankles/feet. 


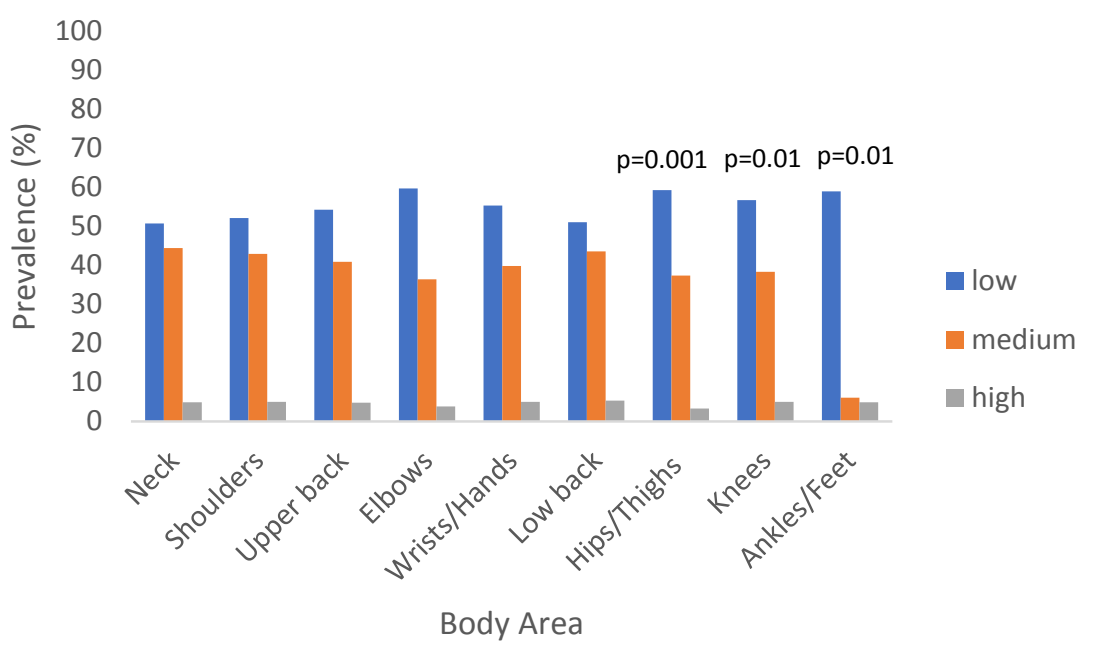

Figure 1: 12-month prevalence of musculoskeletal symptoms by physical activitiy levels $(n=630)$

The 12-month prevalence of symptoms in all body areas was not significantly different between smokers and non-smokers. There was a link between the number of hours sleeping and the 12-month prevalence of shoulder, knee and ankle symptoms with midwives reporting less than 8 hours sleep being more likely to report shoulder $\left(\chi^{2}(1)=4.02, p=0.04\right)$, knee $\left(\chi^{2}(1)=5.61, p=0.01\right)$ and ankle $\left(\chi^{2}(1)=7.42, p=0.006\right)$ symptoms. Significant differences were also found between midwives being carer for an adult and not being a carer, for the 12-month prevalence of elbow $\left(\chi^{2}(1)=6, p=0.01\right)$, wrist/hand $\left(\chi^{2}(1)=7.49, p=0.006\right)$, and knee $\left(\chi^{2}(1)=11.78, p=0.001\right)$ symptoms. Interestingly, no significant differences were found for being carer of a child. There was only one male in the sample group therefore gender was not investigated as a contributory factor.

\section{Work related risk factors for MSD}

An independent-samples t-test showed that there was a significant difference in years practicing in midwifery for upper back ( $\mathrm{t}(625)=-4.8, \mathrm{p}<0.0001)$ and low back (t $(625)=-2.8$, $p=0.005$ ) symptoms. These results suggest that surprisingly midwives reporting such symptoms worked on average fewer years in midwifery. The number of working hours in a week was significantly different for midwives reporting neck ( $t(631)=2.02, p=0.04)$, shoulder $(t(631)=2.51, p=0.01)$ and upper back $(t(631)=2.05, p=0.04)$ symptoms in the 12-month period. Not surprisingly, those who reported such symptoms worked more hours on average. Chi-square test showed a significant difference between shift lengths and the 12month prevalence of low back $\left(x^{2}(2)=11.28, p=0.004\right)$ symptoms, and the severity of upper 
back $\left(x^{2}(2)=7.86, p=0.02\right)$ symptoms; the distribution of prevalence rates by shift length are shown in Figure 2.

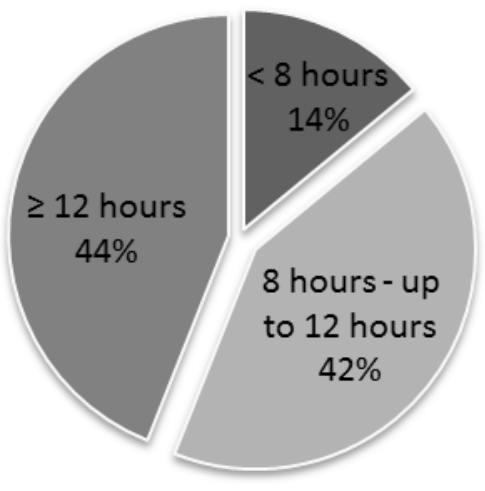

12-month prevalence of low back $\left(\mathrm{n}=627, \mathrm{p}=0.004^{* *}\right)$

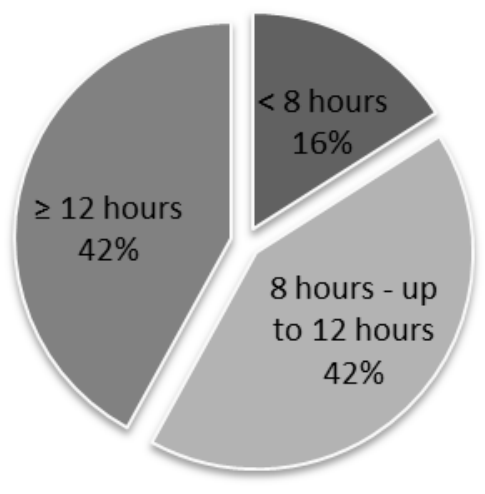

Severity prevalence of upper back $(n=629, p=0.02 *)$

Figure 2: Significant association between prevalence of symptoms by shift length (hours)

Chi square test showed that the proportion of night shifts undertaken in a month was significantly related to knee $(p=0.02)$ and ankle/foot $(p=0.03)$ symptoms; midwives who had fewer night shifts were more likely to report such symptoms. No significant difference was found for the average number of days actively involved in deliveries in 12-month prevalence groups in any body areas.

\section{Psychosocial risk factors for MSD}

For the psychological risk factors, the job satisfaction level (rated 0 to 10 ) significantly differed for the shoulders $(p=0.004)$, low back $(p<0.0001)$ and hips/thighs $(p=0.02)$ 'Yes' and 'No' groups. As expected, job satisfaction levels were lower on average for midwives with musculoskeletal symptoms than those without such symptoms.

With regard to work stress, an independent-samples t-test revealed that the Effort-Reward Imbalance scores were significantly higher in the group reporting shoulder symptoms compared to those not reporting them $(t(610)=2.66, p=0.008)$; midwives with shoulder symptoms tended to report more work stress. Similarly, the mean scores for over commitment significantly differed for the neck $(t(614)=2.75, p=0.006)$, shoulders $(t(614)=4.55, p<0.0001)$, low back $(t(614)=2.27, p=0.02)$ and ankles/feet $(t(614)=2.27$, $p=0.02$ ); midwives reporting such symptoms had higher over commitment scores. 
Logistic regression analysis was used for the low back, neck and shoulders in order to estimate odds ratios (ORs) for each independent variable in the presence of more than one potential predictor. There was a strong correlation $(r=0.7)$ between age and the number of years practicing in midwifery, therefore only age was included in logistic regression analysis not to affect the efficiency (Sperandei, 2014). The results of the logistic regression analysis (Table 4) indicated that low back symptoms were mostly associated with individual factors (age, BMI) and additionally job satisfaction. Age was inversely associated with low back symptoms. Only the variable 'over commitment' was associated with two body areas (neck and shoulders). Increased working hours in a week was a predictor for shoulder symptoms. Those caring for an adult dependent for more than 50 hours a week were 4.54 times more likely to have neck discomfort than those who were not.

\begin{tabular}{|c|c|c|c|}
\hline Factor & $\begin{array}{l}\text { Low back } \\
\text { OR }(95 \% \mathrm{Cl})\end{array}$ & $\begin{array}{l}\text { Neck } \\
\text { OR }(95 \% \mathrm{Cl})\end{array}$ & $\begin{array}{l}\text { Shoulder } \\
\text { OR }(95 \% \mathrm{Cl})\end{array}$ \\
\hline Age & $0.97(0.95-0.99)^{*}$ & & \\
\hline BMI & $1.05(1.00-1.09)^{*}$ & + & \\
\hline Adult carer for $>50$ hours a week & & $4.54(1.33-16.6)^{*}$ & \\
\hline Working hours in a week & & & $1.02(1.00-1.05)^{*}$ \\
\hline Job satisfaction score & $0.89(0.81-0.99)^{*}$ & & \\
\hline Over commitment score & 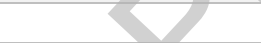 & $1.07(1.01-1.14)^{*}$ & $1.11(1.04-1.18)^{* *}$ \\
\hline
\end{tabular}

${ }^{*} \mathrm{p}<0.05 ;{ }^{* *} \mathrm{p}<0.01 ;{ }^{* *} \mathrm{p}<0.001$

\section{Discussion}

The findings show very high prevalence of musculoskeletal symptoms (91\%) reported by midwives within a 12-month period. Not surprisingly, low back was the most commonly reported body area (71\%), followed by the neck (45\%) and shoulders (45\%). MSD prevalence rates seem to be consistent with other studies, for example, a study of Australian midwives ( $n=729$ ) (Long et al., 2013a), in which 61\% reported low back and 49\% neck discomfort, and a study of Polish midwives ( $n=95)$, in which $67 \%$ indicated having pain in any segment of the spine (Nowotny-Czupryna et al., 2012). The prevalence rates were also considerably higher compared to the UK general population, with 34\% for neck (Palmer et al., 2001) and 37\% for low back symptoms (Papageorgiou et al., 1995). In comparison to the other healthcare professionals, the prevalence rates are not very different, for example dentists who spend most of their working hours with their neck flexed and their shoulder in a fixed position: Rafie et al. (2015) found the 12-month prevalence of neck and shoulder symptoms to be 
$56 \%$ and $44 \%$, respectively $(n=130)$. Lee et al. (2015) also reported the 12 -month prevalence of symptoms among nurses to be most commonly in the low back, neck and shoulders at $54 \%, 41 \%, 34 \%$, respectively. This may be explained by the fact that midwives have similar risk exposures at work with such occupations.

Half of the respondents' work and leisure activities were affected by musculoskeletal symptoms. It is therefore very likely that the discomfort experienced by the staff providing direct patient care will impact on the quality of care provided and/or patient safety as well as on individuals' daily life. In addition, $45 \%$ of the respondents reported that they needed to change jobs/duties and 30\% took sick leave due to MSD. This can result in staff shortages and/or replacement with more inexperienced staff leading to disruptions of care. The effect of sickness absenteeism in the NHS with regard to financial consequences has been well documented (Boorman, 2009). It is known to result in increased work load for the rest of the staff. It is interesting to note that the overall number of MSDs requiring sick leave was very low compared to the number of MSDs reported, particularly for the neck, upper back and elbows. This indicates that the midwives were mostly at work while they were experiencing discomfort, which is called presenteeism and can influence the productivity and safety at work (Aysun and Bayram, 2017).

Age has been commonly associated with MSDs in studies of health professionals, particularly nurses (Alexopoulos et al., 2003; Gopinadh et al., 2013; Jellad et al., 2013; Ribeiro et al., 2017). Contrary to the general expectation of increased age having a detrimental effect on MSD (Ribeiro et al., 2017), the 12-month prevalence of low back symptoms in this study was lower with increasing age. This is consistent with the study of Australian physiotherapists ( $n=536$ ) (Cromie et al., 2000), in which the 20-29 age group reported the highest prevalence rates for upper back $\left(x^{2}(4)=15.27, p=0.004\right)$ and low back $\left(x^{2}(4)=19.02, p=0.001\right)$. Glover et al. $(2005)$ also found similar results in their study of UK physiotherapists ( $n=2688$ ); the majority (59\%) experienced their most serious symptoms aged $<30$ years. There were also similarities with nurses; Tibunu et al. (2010) found that the lowest 12-month prevalence rates of MSD reported by nurses $(n=128)$ who were over 50 years old. A possible explanation suggested by the authors was that senior nurses have less clinically active roles than junior nurses resulting in less exposure to physical working risk factors. The data in this paper supports this idea as the older midwives reported fewer days 
actively involved in birth deliveries for example. Alternatively, these findings might be subject to the 'healthy worker effect', where older midwives who suffered from MSD might have retired or discontinued working and therefore not included in sample groups. Another explanation might be that older midwives are generally more experienced, and therefore more knowledgeable about prevention and coping strategies. This hypothesis helps explain the association between years practicing and period prevalence rates in this present study: those with less experience in midwifery were more likely to report upper back and/or low back symptoms. This explanation was supported by Bork et al. (1996) as the 'survivor effect', in which older individuals develop strategies such as modifying techniques and positions and asking for more support to carry on working in their current roles.

Longer working hours in a week were associated with shoulder symptoms in the logistic regression analysis. This seems to be consistent other research on nurses, for example Lipscomb et al. (2002) found an association between upper body discomfort and working long hours: more than 40 hours a week and/or more than 12 hours a day. Long working hours have also been associated with the risk of obesity in nurses (Chin et al., 2016; Han et al., 2011), which is likely to have an impact on an individuals' musculoskeletal system. The high prevalence of overweight midwives in this current study also corroborates this finding.

Almost $40 \%$ of the respondents reported working 12 hours or more in a shift in the current study. England has a reputation among European countries, of having long shifts for nurses and midwives due to staff shortages (Buscher et al., 2010). Although a significant interaction was found between shift length and 12-month prevalence of low back symptoms $\left(x^{2}(2)=11.28, p=0.004\right)$, with midwives working 8-12 hours $(42 \%)$ or more than 12 hours (44\%) being more likely to report low back symptoms than those working less than 8 hours (14\%); shift duration was not significant in the logistic regression analysis. There are advantages of a 12-hour shift (e.g. more days off, frequent breaks and more social time) (Stone et al., 2006), but longer shifts have been argued to cause fatigue impacting on performance, care quality and safety (Griffiths et al., 2014; Health Safety Executive, 2006; Smith et al., 1998). Mitchell et al. (2000) evaluated the effects of switching to 12-hour from an 8-hour shift on industrial workers, and noted a significant improvement in the social life of the individuals, however there was an increase in error rates at work. 
Psychosocial measures, specifically job satisfaction and stress, were main contributors for developing MSD; job satisfaction was found as a significant risk factor for low back pain. Consistent with these findings, Urquhart et al. (2013) found associations between low job satisfaction, low back pain and time off work in a cross sectional study with 1111 nurses in Australia. It should also be noted that satisfaction at work can also be influenced by other factors in health carers such as reward, professionalism (Hampton and Hampton, 2004), support and mental pressure (Smith et al., 2006).

Over commitment was significantly associated with the risk of neck and shoulder symptoms. This finding was unexpected and suggests that intrinsic work stress is a major factor for this occupational group. According to the effort-reward model, over-committed people cannot withdraw from the responsibility of work, therefore, they spend excessive effort at work (Siegrist et al., 2004). Weyers et al (2006) found in their cross sectional study with nurses $(n=367)$ that $E R I$ was significantly associated with increasing musculoskeletal complaints in the low back, neck and shoulder, whereas over commitment was not. This differs from the findings of the current study, but this could be due to differences between nursing and midwifery roles. Midwives are more prone to continuous work due to the nature of their job and they spend many hours with the pregnant mother, developing close relationships and sympathy, which could lead to over-caring. It is also important to bear in mind that overcommitment could be related to an individual's characteristics, rather than just work related patterns.

In the current study, $60.5 \%$ of the participants were overweight or obese. This result is in line with the general population prevalence rate in England: $58 \%$ of women were over normal weight (Moody and Neave, 2016). Increased BMI was associated with low back symptoms in the logistic regression analysis. However, this finding does not support the previous research of Jensen et al. (2012) who found that BMI and low back pain were not causally related in their prospective cohort study of healthcare workers.

Caring for an adult (for more than 50 hours a week) was found to be a risk factor for neck symptoms (OR: $4.54, \mathrm{Cl}: 1.33$ - 16.6), however the confidence intervals ( $\mathrm{Cl}$ ) were wide indicating that a larger sample size would give a more convincing result for this factor. This result is still in agreement with Long et al. (2013b) in their study of Australian midwives 
$(n=1388)$. They found a $36 \%$ increased risk of neck symptoms for participants caring for an adult dependent. It was suggested by the authors that because most of the midwives are women, they are likely to also have a caring role outside of the work, and therefore this becomes an individual related risk factor for neck symptoms.

The research reported in this paper is unique in terms of exploring MSD and risk factors in UK midwives, but limited in some aspects. The dominance of female population reflected the responses with only one male participant $(\sim 0,2 \%)$, but this rate is proportional for the $0.3 \%$ of male registered midwives in the UK (NMC, 2018). There is potential for response bias in a self-reported questionnaire; participants may over or under report their symptoms (Robson and McCartan, 2016), however there is evidence that self-report of musculoskeletal symptoms with the NMQ questionnaire provides similar results to experts' examinations (Perreault et al., 2008; Takekawa et al., 2015). Non-response bias is another potential concern because people with MSDs may have been more likely to participate. In order to reduce the effect of this limitation, the questionnaire was titled as 'Musculoskeletal Health Survey' rather than 'Musculoskeletal Disorders in Midwives' in order to invite all midwives whether they experienced any MSD or not. This was also emphasised during data collection with a text in bold and bigger font size in the invitation and reminder emails. However, this bias might limit the validity or generalisability of the findings.

An online survey enabled collecting data from a geographically wider sample, however difficulties arose from accessing the survey web page (due to web browser or device differences) and participants having limited access to their emails to reach the online survey link. Another limitation of survey studies is participants being restricted to certain responses (Neale, 2008). It was therefore not possible to explore the reasons behind their responses. Similarly, survey studies restrict the exploration of the physical work place factors such as frequency or duration of awkward and/or static postures, and pushing/pulling/lifting activities. These factors are very prone to recall bias: participants may not remember correctly or be aware of their positions while working. Therefore, future research should be undertaken to address these factors with qualitative and observational studies. 


\section{Conclusion}

This is the first survey of MSDs from a cohort of UK midwives. The findings will help midwives, occupational health experts and healthcare policymakers to prioritise this serious cause of suffering and disability in the UK midwives. The findings support that UK midwives are experiencing high levels of musculoskeletal symptoms, most commonly in the low back, neck and shoulders. Such symptoms affect their activities at work or leisure, result in sickness absence and leaving the profession (staff shortages). Age and years practicing in midwifery have a role in MSD prevalence: younger midwives who had less experience in midwifery were at the highest risk of musculoskeletal symptoms. Midwives having higher $\mathrm{BMI}$ are higher risk of developing low back symptoms. Working longer hours is a risk factor for developing shoulder symptoms. Low job satisfaction and increased work stress have a role for developing MSD. This research highlights the importance of preventing MSDs in midwifery and its potential impacts. The results are crucial to promote risk-awareness and actions for risk management. 


\section{References}

Alexopoulos, E.C., Burdorf, A., Kalokerinou, A., 2003. Risk factors for musculoskeletal disorders among nursing personnel in Greek hospitals. International Archives of Occupational and Environmental Health 76, 289-294.

Anderson, S.P., Oakman, J., 2016. Allied Health Professionals and Work-Related Musculoskeletal Disorders: A Systematic Review. Safety and Health at Work 7, 259267.

Ball, L., Curtis, P., Kirkham, M., 2002. Why Do Midwives Leave?: Talking to Managers. Royal College of Midwives.

Bartys, S., 2003. Psychosocial factors at work, musculoskeletal disorders and the implementation of guidelines principles. University of Huddersfield.

Boorman, S., 2009. NHS Health and Well Being. Final Report. London Department of Health.

Bork, B.E., Cook, T.M., Rosecrance, J.C., Engelhardt, K.A., Thomason, M.-E.J., Wauford, I.J., Worley, R.K., 1996. Work-related musculoskeletal disorders among physical therapists. Physical Therapy 76, 827-835.

Bureau of Labour Statistics, 2015. Employer-Reported Workplace Injuries and IIInesses 2014.

Buscher, A., Sivertsen, B., White, J., 2010. Nurses and Midwives: A Force for health: Survey on the situation of nursing and midwifery in the Member States of the European Region of the World Health Organization 2009. WHO Regional Office for Europe Google Scholar.

Chin, D.L., Nam, S., Lee, S.-J., 2016. Occupational factors associated with obesity and leisuretime physical activity among nurses: A cross sectional study. International Journal of Nursing Studies 57, 60-69.

Cromie, J.E., Robertson, V.J., Best, M.O., 2000. Before starting the analyses, the data were screened in terms of errors and missing variables. It was not the case that all participants answered all questions. Physical Therapy 80, 336-351.

Engkvist, I.-L., Hjelm, E.W., Hagberg, M., Menckel, E., Ekenvall, L., 2000. Risk indicators for reported over-exertion back injuries among female nursing personnel. Epidemiology 519-522.

Gatchel, R.J., Peng, Y.B., Peters, M.L., Fuchs, P.N., Turk, D.C., 2007. The biopsychosocial approach to chronic pain: scientific advances and future directions. Psychological Bulletin 133, 581.

Glover, W., McGregor, A., Sullivan, C., Hague, J., 2005. Work-related musculoskeletal disorders affecting members of the Chartered Society of Physiotherapy. Physiotherapy 91, 138-147.

Gopinadh, A., Devi, K.N.N., Chiramana, S., Manne, P., Sampath, A., Babu, M.S., 2013. Ergonomics and musculoskeletal disorder: as an occupational hazard in dentistry. The Journal of Contemporary Dental Practice 14, 299.

Griffiths, P., Dall'Ora, C., Simon, M., Ball, J., Lindqvist, R., Rafferty, A.-M., Schoonhoven, L., Tishelman, C., Aiken, L.H., 2014. Nurses' shift length and overtime working in 12 European countries: the association with perceived quality of care and patient safety. Medical Care 52, 975.

Hampton, G.M., Hampton, D.L., 2004. Relationship of professionalism, rewards, market orientation and job satisfaction among medical professionals: The case of Certified Nurse-Midwives. Journal of Business Research 57, 1042-1053.

Han, K., Trinkoff, A.M., Storr, C.L., Geiger-Brown, J., 2011. Job stress and work schedules in 
relation to nurse obesity. Journal of Nursing Administration 41, 488-495.

Hauke, A., Flintrop, J., Brun, E., Rugulies, R., 2011. The impact of work-related psychosocial stressors on the onset of musculoskeletal disorders in specific body regions: A review and meta-analysis of 54 longitudinal studies. Work Stress 25, 243-256.

Health Safety Executive, 2006. Managing shiftwork - Health and safety guidance. HSE books $1-45$.

Hignett, S., 2003. Intervention strategies to reduce musculoskeletal injuries associated with handling patients: a systematic review. Occupational and Environmental Medicine 60, e6-e6.

Hignett, S., 1996. Manual handling risks in midwifery: identification of risk factors. British Journal of Midwifery 4, 590-596.

Jellad, A., Lajili, H., Boudokhane, S., Migaou, H., Maatallah, S., Frih, Z.B.S., 2013. Musculoskeletal disorders among Tunisian hospital staff: Prevalence and risk factors. The Egyptian Rheumatologist 35, 59-63.

Jensen, J.N., Holtermann, A., Clausen, T., Mortensen, O.S., Carneiro, I.G., Andersen, L.L., 2012. The greatest risk for low-back pain among newly educated female health care workers; body weight or physical work load? BMC Musculoskeletal Disorders 13, 87.

Kuorinka, I., Jonsson, B., Kilbom, A., Vinterberg, H., Biering-Sørensen, F., Andersson, G., Jørgensen, K., 1987. Standardised Nordic questionnaires for the analysis of musculoskeletal symptoms. Applied Ergonomics 18, 233-237.

Laisné, F., Lecomte, C., Corbière, M., 2013. Biopsychosocial determinants of work outcomes of workers with occupational injuries receiving compensation: a prospective study. Work 44, 117-132.

Lang, J., Ochsmann, E., Kraus, T., Lang, J.W.B., 2012. Psychosocial work stressors as antecedents of musculoskeletal problems: a systematic review and meta-analysis of stability-adjusted longitudinal studies. Social Science and Medicine 75, 1163-1174.

Lee, S., Lee, J.H., Gershon, R.R.M., 2015. Musculoskeletal symptoms in nurses in the early implementation phase of california's safe patient handling legislation. Research in Nursing and Health 38, 183-193.

Lipscomb, J.A., Trinkoff, A.M., Geiger-Brown, J., Brady, B., 2002. Work-schedule characteristics and reported musculoskeletal disorders of registered nurses. Scandinavian Jo urnal of Work, Environment and Health 394-401.

Long, M.H., Bogossian, F.E., Johnston, V., 2013a. Functional consequences of work-related spinal musculoskeletal symptoms in a cohort of Australian midwives. Women and Birth 26, e50-e58.

Long, M.H., Johnston, V., Bogossian, F., 2012. Work-related upper quadrant musculoskeletal disorders in midwives, nurses and physicians: a systematic review of risk factors and functional consequences. Applied Ergonomics 43, 455-467.

Long, M.H., Johnston, V., Bogossian, F.E., 2013b. Helping women but hurting ourselves? Neck and upper back musculoskeletal symptoms in a cohort of Australian Midwives. Midwifery 29, 359-367.

Mitchell, R.J., Williamson, A.M., 2000. Evaluation of an 8 hour versus a 12 hour shift roster on employees at a power station. Applied Ergonomics 31, 83-93.

Moody, A., Neave, A., 2016. Health Survey for England 2015. Adult overweight and obesity. Neale, J., 2008. Research methods for health and social care. Palgrave Macmillan.

NHS, 2011. Start Active, Stay Active, Report. Available at:

https://doi.org/https://www.gov.uk/government/uploads/system/uploads/attachment 
_data/file/216370/dh_128210.pdf

NHS Employers, 2015. 2015 NHS Pension Scheme. Available at:

http://www.nhsemployers.org/your-workforce/pay-and-reward/pensions/new-2015scheme\#one

NMC, 2018. The NMC register.Nursing and Midwifery Council. Available at: https://www.nmc.org.uk/globalassets/sitedocuments/other-publications/the-nmcregister-2018.pdf

Nowotny-Czupryna, O., Naworska, B., Brzęk, A., Nowotny, J., Famuła, A., Kmita, B., Bąk, K., 2012. Professional experience and ergonomic aspects of midwives' work. International Journal of Occupational Medicine and Environmental Health 25, 265-274.

Office for National Statistics, 2018. Sickness absence in the UK labour market. Available at: https://www.ons.gov.uk/employmentandlabourmarket/peopleinwork/employmentan demployeetypes/datasets/sicknessabsenceinthelabourmarket

Palmer, K.T., Walker-Bone, K., Griffin, M.J., Syddall, H., Pannett, B., Coggon, D., Cooper, C., 2001. Prevalence and occupational associations of neck pain in the British population. Scandinavian Journal of Work, Environment and Health 49-56.

Papageorgiou, A.C., Croft, P.R., Ferry, S., Jayson, M.I. V, Silman, A.J., 1995. Estimating the prevalence of low back pain in the general population: evidence from the South Manchester Back Pain Survey. Spine (Phila. Pa. 1976). 20, 1889-1894.

Perreault, N., Brisson, C., Dionne, C.E., Montreuil, S., Punnett, L., 2008. Agreement between a self-administered questionnaire on musculoskeletal disorders of the neck-shoulder region and a physical examination. BMC Musculoskeletal Disorders 9, 34.

Rafie, F., Zamani Jam, A., Shahravan, A., Raoof, M., Eskandarizadeh, A., 2015. Prevalence of upper extremity musculoskeletal disorders in dentists: symptoms and risk factors. Journal of Environmental and Public Health 2015.

RCM (2015) 'State of Maternity Services Report 2015', pp. 1-16. Available at: https://www.rcm.org.uk/sites/default/files/RCM State of Maternity Services Report 2015.pdf.

RCM, 2018. State of Maternity Services Report 2018, The Royal College of Midwives. Available at:

https://www.rcm.org.uk/sites/default/files/ENGLAND\%20SOMS\%202018\%20\%20FINAL\%20\%2803.09.2018\%29.pdf

RCM, 2016. State of Maternity Services Report 2016 1-20. Available at: https://www.rcm.org.uk/sites/default/files/SoMS Report 2016_New Design_aw.pdf

Ribeiro, T., Serranheira, F., Loureiro, H., 2017. Work related musculoskeletal disorders in primary health care nurses. Applied Nursing Research 33, 72-77.

Robson, C., McCartan, K., 2016. Real world research. John Wiley \& Sons.

Russo, A., Murphy, C., Lessoway, V., Berkowitz, J., 2002. The prevalence of musculoskeletal symptoms among British Columbia sonographers. Applied Ergonomics 33, 385-393.

Saxon, S. V, Etten, M.J., Perkins, E.A., 2014. Physical change and aging: A guide for the helping professions. Springer Publishing Company.

Siegrist, J., Li, J., Montano, D., 2013. Psychometric properties of the effort-reward imbalance questionnaire. Duesseldorf University: Department of Medical Sociology FoM.

Siegrist, J., Starke, D., Chandola, T., Godin, I., Marmot, M., Niedhammer, I., Peter, R., 2004. The measurement of effort-reward imbalance at work: European comparisons. Social Science and Medicine 58, 1483-1499.

Siegrist, J., Wege, N., Pühlhofer, F., Wahrendorf, M., 2009. A short generic measure of work 
stress in the era of globalization: effort-reward imbalance. International Archives of Occupational and Environmental Health 82, 1005.

Smedley, J., Inskip, H., Trevelyan, F., Buckle, P., Cooper, C., Coggon, D., 2003. Risk factors for incident neck and shoulder pain in hospital nurses. Occupational and Environmental Medicine 60, 864-869.

Smith, D.R., Wei, N., Zhang, Y.-J., Wang, R.-S., 2006. Musculoskeletal complaints and psychosocial risk factors among physicians in mainland China. International Journal of Industrial Ergonomics 36, 599-603.

Smith, L., Folkard, S., Tucker, P., Macdonald, I., 1998. Work shift duration: a review comparing eight hour and 12 hour shift systems. Occupational and Environmental Medicine 55, 217-229.

Sperandei, S., 2014. Understanding logistic regression analysis. Biochemica medica: Biochema medica 24, 12-18.

Stone, P.W., Du, Y., Cowell, R., Amsterdam, N., Helfrich, T.A., Linn, R.W., Gladstein, A., Walsh, M., Mojica, L.A., 2006. Comparison of nurse, system and quality patient care outcomes in 8-hour and 12-hour shifts. Medical Care 44, 1099-1106.

Takekawa, K.S., Goncalves, J.S., Moriguchi, C.S., COURY, H.J.C.G., 2015. Can a selfadministered questionnaire identify workers with chronic or recurring low back pain? Industrial Health 53, 340-345.

Tinubu, B.M.S., Mbada, C.E., Oyeyemi, A.L., Fabunmi, A.A., 2010. Work-related musculoskeletal disorders among nurses in Ibadan, South-west Nigeria: a crosssectional survey. BMC Musculoskeletal Disorders 11, 12.

Trinkoff, A.M., Le, R., Geiger-Brown, J., Lipscomb, J., Lang, G., 2006. Longitudinal relationship of work hours, mandatory overtime, and on-call to musculoskeletal problems in nurses. Americal Journal of Industrial Medicine 49, 964-971.

Urquhart, D.M., Kelsall, H.L., Hoe, V.C.W., Cicuttini, F.M., Forbes, A.B., Sim, M.R., 2013. Are psychosocial factors associated with low back pain and work absence for low back pain in an occupational cohort? The Clinical Journal of Pain 29, 1015-1020.

Van Mechelen, W., Hlobil, H., Kemper, H.C.G., 1992. Incidence, severity, aetiology and prevention of sports injuries. Sports Medicine 14, 82-99.

Weyers, S., Peter, R., Boggild, H., Jeppesen, H.J., Siegrist, J., 2006. Psychosocial work stress is associated with poor self-rated health in Danish nurses: a test of the effort-reward imbalance model. Scandinavian Journal of Caring Sciences 20, 26-34.

World Health Organization, 2016. Obesity and overweight fact sheet. Available at: https://www.who.int/news-room/fact-sheets/detail/obesity-and-overweight (accessed on 8.10.18).

World Health Organisation, 2018. Nursing and midwifery fact sheet. Available at: https://www.who.int/news-room/fact-sheets/detail/nursing-and-midwifery (accessed on 20.03.19).

Yazdani, A., Neumann, W.P., Imbeau, D., Bigelow, P., Pagell, M., Wells, R., 2015. Prevention of musculoskeletal disorders within management systems: A scoping review of practices, approaches, and techniques. Applied Ergonomics 51, 255-262. 


\section{Acknowledgement}

This research did not receive any specific grant from funding agencies in the public, commercial, or not-for-profit sectors.

We gratefully thank to all midwives who were volunteer to take part in the study. 